für die Tatsache finden, daB solche mittels Seife hergestellte Emulsionen meist entmischt werden, wenn man sie längere Zeit stehen läßt, wogegen bei richtig, also mittels fester Partikel (etwa mit einem basischen Sulfat) hergestellten Emulsionen, sofern kein auf diese letzteren schädlich einwirkender Körper vorhanden ist, eine Entmischung noch niemals beobachtet wurde.

Zus a m menfassung: Obwohl eine hohe Viskosität und eine geringe Oberflächenspannung einer Flüssigkeit die Emulgierung von Oel darin erleichtern mögen, kann doch eine
Emulgierung aurch in einer Flüssigkeit zustande kommen, die keine dieser Eigenschaften aufweist. Die einzige oder doch hauptsächliche Ursache der Emulgierung scheint vielmehr die Gegenwart kleiner Pattikel einerim Emulgierungsmittel unlöslichen Substanz zu sein, die die Oeltropfchen mit einer Haut umgeben, die sie an der Vereinigung hindert. Damit solche Partikel die Fähigkeit haben, Emulsionen zu bilden, dürfen sie nur eine geringe Tendenz zur Vereinigung miteinander zeigen, müssen leichter von dem Lösungsmittel als von Oel benetzt werden und dürfen nicht kristallinisch sein.

\title{
Ueber Emulsionsbildung bei der Vermischung wässeriger Lösungen gewisser gelatinierender Kolloide.
}

\author{
Von M. W. Beijerinck, Delft.
}

(Eingegangen am 19. Mirz 1910)

Vor kurzem habe ich ein Enzym beschrieben'), welches aus Rohrzucker und aus Raffinose sowohl in Nährlösungen wie in Agarplatten einen nicht diffundierenden, offenbar grobmolekularen Schleim erzeugt, welcher. die Polarisationsebene nach links dreht und mit Lippmann's Lävulan verwandt ist. Das Enzym wird durch einige allgemein verbreitete sporenbildende Erdbakterien hervorgebracht, wie Bacillus mesentericus (der Heubazillus), B. megatherium und besonders B. emulsionis, welcher in Rohrzucker selbst allgemein ist. Alle diese Bakterien könnten "Emulsionsbakterien“ genannt werden.

Die Erscheinung ist sehr charakteristisch und besteht darin, daB in Rohrzuckernährlösungen durch die genannten Arten eine ausgesprochene, aus Schleimtröpfchen bestehende weibliche Emulsion entsteht, welche auf und in Agarplatten bis auf Zentimeterentfernung ringsum der Kolonien ebenfalls leicht sichtbar wird. Dieser Schleim ist nicht diffusionstähig, muB deshalb an Ort und Stelle im Agar entstehen, was sicher durch ein Enzym stattfindet. Dieses Enzym wurde Viskosaccharase genannt, und ist vielleicht das erste Beispiel eines außerhalb der Zelle synthetisch wirkenden Enzyms. Daß hier wirklich Synthese stattfindet, folgt aus der MolekulargröBe des

1) Viscosaccharase, An enzyme, which produces slime from cane-sugar. Proceedings Acad. of Sciences, Amsterdam, Januar 1910, S. 635 and May 1910. Mit Abbildung.
Schleimes, welcher biologisch als Wandsubstanz aufzufassen ist.

Die so aufgedeckte Emulsionserscheinung veranlaBt mich, auf eine ähnliche Eigentümlichkeit gewisser anderer, und zwar gelatinierender Körper aufmerksam zu machen, welche ich allerdings schon vor einigen Jahren beschrieben habe ${ }^{2}$, doch für manchen Leser dieser Zeitschrift neu und nicht ohne Interesse sein dürfte.

1. Die Emulsionserscheinung beim Vermischen wasseriger Kolloidlösungen.

Wenn man nicht allzusehr verdünnte Losungen von Agar und Gelatine in heißem Wasser, z.'B. eine 10 proz. Gelatine- und eine 2 proz. Agarlösung, zu vermischen versucht, bemerkt man, daß dieses trotz längeren Schüttelns niemals vollständig gelingt, sondern das diejenige Lösung, wovon man dic geringste Quantität verwendet hat, als kleine, mikroskopisch nachweisbare Tröpfchen schwebend verbleibt in dem grötieren Volum der zweiten Lösung. Oft enthalten die schwebenden. Tröptchen wieder kleinere Tröpfchen der anderen l.ösung. Beim Erstarren wird dieser Zustand fixiert, ist dann aber etwas schwieriger $2 \mathrm{u}$ beobachten, weil das Lichtbrechungsvermögen beider Körper nur wenig verschieden ist und weil dann relative Bewegungen ausgeschlossen sind, welche im

7) Ueber eine Eigenttimlichkeit der 16slichen Starke. Centralbl. f. Bakteriologie 2. Abt., 8, 627 (1893). 
flüssigen Medium die Differenz deutlicher machen. Allenfalls kann man sich jedoch bei sehr schiefer Beleuchtung von dem beschriebenen Tatbestande überzeugen.

Verwendet man anstatt Agar eine 10 proz. Lösung von losslícher Stärke, welche in einer 10 proz. Gelatinelösung aufgeschüttelt wird, so wird die Erscheinung noch deutlicher und kann, wie ich das früher beschrieben habe, zur Herstellung eines künstlichen "Zellgewebes" verwendet werden, worin der .Zellinhalt" aus Starke, die "Zellwände* aus Gelatine bestehen, oder umgekehrt, je nachdem wenig Stärkelösung und viel Gelatine oder viel Stärke und wenig Gelatinelossung vermischt werden.

Ueber das genauere $\mathrm{MaB}$ der dabei in Betracht kommenden Mengenverhaltnisse belehrt uns eine bemerkenswerte Mitteilung von Wa. Ostwald ${ }^{3}$ ), woraus hervorgeht, daB zwischen 74 und 26 Proz. der einen Lossung beide $\mathrm{Zu}$ sth̆nde möglich sind, während nur dann, wenn der Prozentgehalt der einen Lösung unter ca. 26 Proz. verbleibt, diese nur allein als "Inhalt", das heiBt als disperse Phase vorkommen kann.

Weil das spezifische Gewicht einer Stärkelösung höher ist wie das der gleich konzentrierten Gelatine, kann man bei deren Vermischung auch beobachten, wie die aufgeschüttelten Tröpfchen der Stărkelösung beim ruhigen Stehen nach unten sinken und zur Bildung einer ziemlich klaren oberen Gelatineschicht veranlassen.

Vermittelst der Jodreaktion stellt sich heraus, daß die Gelatinelösung zwischen den

3) Beltrăge zur Kenntnis der Emulsionen. Koll.Zeltschrift 6, 103 (1910). Ostwald sagt, die Minimumzahl betrage ca. 22 Proz. Dieses ist jedoch nicht richtig, wie aus folgender Betrachtung hervorgeht. Stapelt man gleiche Kugeln zu einem drei- oder viereckigen Stapel aufeinander, wobei eine und dieselbe möglichst dichte Anordnung entsteht, so beruhrt jede Kugel 12 andere. Bringt man durch die 12 Beribhrungspunkte Tangentialebenen, so bilden diese zusammen einen regulären Rhomboeder. Stellt man die Seitenlänge dieses Rhomboeders gleich Eins, so wird dessen Inhalt gleich $\frac{16}{9} \sqrt{3}$, whrend der Inhalt der eingeschriebenen Kugel in dieser Einheit $\frac{8}{27} \pi \sqrt{6}$ wird. Das Verhaltnis beider ist das gesuchte Mab, weil die Rhomboeder genau den Raum ausfullen. Dieses Ver. haltnis ist aber $-\frac{\pi}{3 \sqrt{2}}$, was in Prozenten auskommt auf ca. 74,04 fir die Kugelinhalte und ca. 26 fur die Zwischenräume. Bei kubischer Aufstapelung wird das gleiche Verhaltnis $\frac{\pi}{6}$, also ca. 52 Proz. für die Kugeln und ca. 48 Proz. für die Zwischenrăume. (Vgl. hierzu die Notiz Wa. Ostwalds auf $S .64$ dieses Heftes.)
Stärketröpfchen eine schwache blaue Färuung annimmt, so dat eine Spur Stärke als wirklich aufgelöst $z u$ betrachten ist. Umgekehrt enthalten die Stärketröpfchen auch ein wenig Gelatine in wirklicher Lösung.

Selbst sehr verdünnte Lösungen gut angefertigter lösticher Stärke 4), z. B. von 0,1 Proz. und weniger, bleiben in Gelatine emulsioniert.

Mit Agar und Stärke gelingt die Reaktion nicht, offenbar weil sich nicht mehr wie 2 Proz. Agar lossen läBt, welches noch in der Stärkelösung gelöst bleiben kann. Auch dieser Um. stand scheint mir sehr bemerkenswert.

DaB die .Emulsionserscheinung " eine ziemlich unerwartete ist, geht $z$. B. aus folgender Bemerkung $\mathrm{Bütschli's} \mathrm{hervor}{ }^{5}$ ): "Dieses für zwei wăsserige Lösungen sehr eigentümliche Verhalten, das mir, offen gestanden, wenig wahrscheinlich yorkam, konnte ich zu meiner Ueberraschung . . . bestätigen." Er gibt eine Beschreibung dieser Beobachtungen, ohne den meinigen neue hinzuzufïgen und ohne eine Erklärung zu versuchen. lch glaube, und eben darum erwähne ich Bütschli's Mitteilung, dab, wenn er sich mit diesen Versuchen eingehender beschäftigt hătte, er seiner "Schaumstrukturhypothese " eine ganz andere Form gegeben und besonders dieselbe nur auf leicht sichtbare mikroskopische Verhältnisse, und nicht auf amikroskopisches Gebiet angewandt haben würde.

2. Erstarren der Emulsionen.

Das Gemisch der zwei Kolloidlosungen, wie Agar und Gelatine, verhält sich beim Erstarren den reinen Lösungen beider Substanzen ganz ahnlich. Doch verdient in dieser Beziehung tolgendes bemerkt zu werden.

Einige Beobachter nehmen an, daB der ErstarrungsprozeB einer Gelatine- oder Agarlöung auf die Verschmelzung der kleinen Tröpfchen der dispersen Phase zu gröBeren beruht, wodurch die tatsächlich beobachtete Vergrößerung der inneren Reibung beim Annähern des

4) Die Bereitung geschieht wie folgt: Kartoffelstärke wird mit starker Salzsăure übergossen und einige Zeit in der Kalte aufbewahrt. Nach einigen Tagen oder Stunden, je nach der Salzsturekonzentration, kann die Stărke beim Kochen mit Wasser sich vollständig klar und durchsichtig losen und beim $\mathrm{Ab}$ kihlen porzellanweiB undurchsichtig erstarren. Zur Beseitigung der Salzsăure wird das Praparat mit sehr viel destllitiertem Wasser ausgewaschen, woran anfangs ein wenig Natriumkarbonat zugegeben war.

5) Untersuchungen aber mikroskopioche Strukturen (Leipzig 1898), 251 . 
Erstarrungspunktes zu erklären wäre. Bei unserenı künstlichen Gemisch ist jedoch, wenn man sich der Erstarrungstemperatur annähert, von einer solchen Verschmelzung der Tröpfchen nichts zu sehen, grobe und feine Emulsionen erstarren bei gleichen Temperaturen ohne jede bemerkbare Struktarveränderung. Es findet hier, soweit sichere Beobachtungen darüber Aufschlub geber können, nichts Besonderes statt. Ob die TröpfchengröBe gering oder beträchtlich ist und ob diese sich wohl oder nicht ändert, hat auf Erstarrungstemperatur und Viskosităt jedenfalls nur einen sehr geringen Einflub. Die Auffassung, daB das Erstarren gelöster quellbarer Körper im allgemeinen der Vergrößerung der hypothetischen amikroskopischen Tröpfchen der dispersen Phase parallel gehe oder darauf beruhe, kann ich deshalb zurzeit noch nicht als wahrscheinlich betrachten. Ueberhaupt scheint mir die Hypothese der Emulsionsstruktur der Kolloidlösungen, so wichtig und interessant dieselbe sicher ist, sehr schwach begründet. Nach meiner Ansicht sind konzentrierte Rohrzucker- oder Maltoselösungen physikalisch vollständig vergleichbar mit konzentrierten Gelatine- oder Agarlösungen. So lassen die erstecen sich ebensogut wie die letzteren mit sehr konzentriertem Alkohol als Emulsionen präzipitieren, und doch glaube ich nicht, dab die Chemiker eine Zuckerlösung ohne weiteres als Emulsion auffassen. Warum dieses dann wohl bezüglich Agar, Gelatine oder Stärke geschehen muB, finde ich nicht deutlich. Doch will ich nicht verkennen, dab die mechanische Verkleinerung $z$. B. einer Agaremulsion in Gelatine schlieblich zu einer Art Pseudolösung führen könnte, welche die Struktur einer Lösung eines Emulsionskolloids nach der geläufigen Vorstellung, besitzen könnte. $O b$ die mit der Krümmung steigende Oberflächenspannung der Tröpfchen an dieser Verkleinerung nicht bald ein Ende stellen sollte, scheint mir jedoch fraglich. Jedenfalls konnte ich beirn Kochen meiner Emulsionen, wie lange auch fortgesetzt, die Tröpfchengröße schließlich nicht mehr verringern, immer blieben dieselben grob mikroskopisch

\section{Osmotisches Gleichgewicht in den Kolloidgemischen.}

Betrachtet man die wasseranziehende Kraft der Tröpfchen inbezug auf ihre Umgebung. so ergibt sich folgendes.

Zunächst mul bemerkt werden, dat eine eigentliche Diffusion bei unseren Versuchen von der einen in die andere Phase nicht stattfinden kann. Daraus folgt jedoch nicht, dafs die relativen: Konzentrationen unverändert bleiben sollten. Die Tröpfchen der Stărkelösung oder des Agars, welche in der Gelatinelösung schweben, müssen nämlich mit letzterer im osmotischen Gleichgewicht stehen oder jedenfalls nach einiger Zeit ein solches Gleichgewicht erreichen. So lange sie dieses nicht tun, mug notwendigerweise eine Wasserbewegung stattfinden, welche nach der Gelatinelösung gerichtet ist, wenn darin ein höherer osmotischer Druck herrscht, wie in den Stärke- oder Agartröpfchen, und umgekehrt. Im ersteren Falle müssen die Tröpfchen kleiner, im zweiten Falle müssen dieselben gröber werden. Nennen wir eine solche Lösung eine "kritische*, wenn eine der beiden Phasen zu ca. 26 Proz. gegenwärtig ist, so muß, wenn das Volumen der Tröpfchen dieser Phase kleiner wird, unmöglich ein Zustand zu erreichen sein, worin dieser Anteil als disperse Phase hervortritt. Wird das Volum desselben jedoch vergrößert durch Wasserübertritt aus dem Dispersionsmittel in dieselbe, so wird sich das Verhalten umkehren können, denn wir erreichen nun das zwischen ca. 26 Proz. und 74 Proz. gelegene Ostwald'sche Gebiet, wobei beide Phasen einander ersetzen können. Unter Umständen wird dieses zu einer experimentellen Entscheidung bezüglich der GröBe des osmotischen Druckes solcher Lösungen führen können.

Im speziellen Falle der löslichen Stärke wird letzteres noch dadurch möglich sein, daß die Tröpfchen einer schwach konzentrierten Stärkelösung ein geringeres spezifisches Gewicht, wie diejenigen einer konzentrierten Gelatinelösung haben können, während wir früher sahen, daB konzentrierte Stärkelösungen viel schwerer wie Gelatine sind: Bei bestimmten Versuchsbedingungen werden also anfangs schwebende Stärketröpfchen nach unten sinken können infolge osmotischer Wasserentziehung.

4. Das Auflösen eines trockenen Kolloides in einer anderen Kolloidlösung.

Läbt man für die eine der beiden Lösungen den zu emulsionierenden Körper selber in trockenem Zustande an deren Stelle kommen, so ăndern sich die zur Beobachtung kommenden Erscheinungen etwas. Versucht man z. B. trockene Gelatine in einer Agarlösung durch Erhitzen zu lösen, so stößt man auf Schwierigkeiten, und wie lange man auch das Kochen fortsetzt, niemals bekommt man eine so gleichmäßige 
Verteilung, wie beim Schütteln schon vorher dargestellter Lösungen beider Substanzen. Beim Erstarren kann mar, auch keine gut zusammenhängende Platte bekommen, jedoch nur kleisterartige, unregelmäBig durchfeuchtete Massen, welche aus Klumpen und Kugeln bestehen.

Auch hier mub die Erklärung allerdings teilwcise in der Unmöglichkeit dar Diffusion des einen Kolloids in das andere gesucht werden. Jedoch sind dabei auch folgende Umstände zu berücksichtigen, welche mit dem Streben nach einem $Q$ uellungsgleichgewicht zusaminenhängen.

Beim Kontakte z. B. von trockenem Agar mit flüssiger Gelatinelösung wird erstere Substanz der zweiten anfangs Wasser entziehen und dadurch stark aufquellen. Je weiter diese Quellung fortschreitet, desto schwächer wird die saugende Kraft des Agars jedoch werden, und bald wird der Augenblick kommen, dab das Agar die schwache, jedoch nicht ganz fehlende wasseranziehende Kraft der Gelatinelösung nicht mehr äberwinden kann. Der Saugkrait des Agars setzen sich in diesem Falle offenbar zwei Kräfte entgegen: der osmotische Druck der 10 proz. Gelatinelosung, weicher denjenigen des nur bis ca. 2 Proz. Ioslichen Agars übertrifft, und zweitens der mechanische Widerstand, welchen die relativ konzentrierte Gelatinelossung auf die Volumvergrobßerung des Agars, welche nur mit einer sehr schwachen Kraft stattfindet, ausübt.

Wie auberordentlich klein die Kraft ist, womit 2 Proz. Agar das Wasser zurückhält, geht aus folgender Beobachtung hervor. Wenn man aus einer frisch gegossenen und eben erstarrten Agarlosung ein Stück herausschneidet und dieses biegt, so wird man sehen, daB die leiseste mechanische Krümmung auf der konkaven Seite das flüssige Wasser in kleinen Tropfen heraustreten läßt. Ja die leiseste Berührung einer solchen Platte hat Wasseraustritt zur Folge; die geringste Erwärmung hat einen gleichen Effekt und nach meiner Meinung kann diese Erscheinung Licht werfen auf die Filtration fliussigen Wassers aus allerlei Pflanzenteilen und selbst die Saftsteigung in den Băumen erklären, wobei allerdings angenommen werden muB, daß das Protoplasma, seiner Struktur nach, mit erstarrtem Agar zu vergleichen ist und die Kontraktilität desselben die für den Wasseraustritt notwendigen lokalen Druckverschiedenheiten hervorruft.

Auf ähnliche Weise wie bei den Losungsversuchen von Agar in Gelatine oder umge- kehrt wird man finden, dak Kartoffelstärkekörner, velche beim Verkleisterungsprozesse in reinem Wasser sehr schnell anschwellen (während nur eine Spur der Granulose in Lösung geht) beim Aufkochen 2. B. in 10proz. Gelatinelösung, viel weniger quellen, wie sich durch mikroskopische Messung leicht feststellen läBt.

\section{Quellungsgleichgewicht und Doppelbrechung.}

Obschon die nun zu besprechende Beobachtung nur indirekt mit der Fmulsionserscheinung verbunden ist, glaube ich dennoch, daß die Erörterung derselben imstande ist, weiteres Licht auf die vielen hier in Betracht kommenden Fragen zu werfen.

Die oben erörterte wasseranziehende Kraft zwischen den beiden Phasen der Doppelkolloidemulsion besteht ebensogut im flüssigen wie im erstarrten Zustande. DaB dadurch Erscheinungen der Doppeibrechung des polarisierten Lichtes hervorgerufen werden können, ergibt sich aus folgendem Versuche.

Man giebe in eine Glasschale eine dünne Schicht einer konzentrierten z. B. 20 proz. Gelatinelösung, man lasse erstarren und schneide aus der Platte ein Stück Gelatine heraus, welches entfernt wird. Das so erhaltene Loch wird nun vollgegossen mit einer verdünnten Gelatinelosung, z. B. eine von 2 bis 5 Proz., und $z$ war in der Weise, daB man wieder eine ebene Fläche bekommt. Man lasse wieder erstarren und lasse die heterogene Platte einige Zeit stehen.

Wie zu erwarten, entzieht die konzentrierte Gelatine der verdünnten Wasser; die zunächst sichtbare Folge davon ist die Entstehung eines erhaberen Walles neben der Trennungslinie in der 20 proz. Gelatine und einer tiefen Binsenkung in der 2 prozentigen. Dieses muß offenbar auf Wasserbewegung beruhen, wodurch die konzentrierte Gelatine verdünnt, die verdünnte konzentriert wird, und anscheinend mul dieses so lange fortgehen, bis auf beiden Seiten der Trennungslinie eine gleiche Gelatinekonzentration herrscht, weil erst dann Quellungsgleichgewicht herrschen kann. Die zweite Eigentümlichkeit, welche dabei zur Beobachtung kommt, besteht nun darin, dab die anfangs isotropen Gelatinen verschiedener Konzentration, beide doppelbrechend geworden sind, und zwar entgegengesetzt, so dab sich bezüglich polarisiertem Lichte die eine positiv, die andere negativ verhält. Offenbar ist die Spann* ungsverschiedenheit, welche infolge der Wasser- 
bewegung entstanden ist, die Ursache dieser Doppelbrechung. Es herrscht nämlich in der geschwollenen Gelatine ein Druckzustand, in der eingesunkenen eine Spannung, wie das die für Druck empfindlichen Bakterienarten so überzeugend beweisen, indem dieselben in der Einsenkung parallel, im erhabenen.Wall senkrecht auf die Trennungslinie wachsen, wenn man anstatt reiner Gelatine eine geeignete Nährgelatine verwendet.

Nach meiner Meinung handelt es sich hierbei um eine Erscheinung, welche eine Erklärung gibt von sehr vielen Fällen, wobei Doppelbrechung in organischen Strukturen beobachtet wird. Als solche wünsche ich die Stärkekörner anzuführen, welche bekanntlich aus Schichten ungleichen Wassergehaltes bestehen, und eben darin dürfte nach dem Vorstehenden ein ausreichender Grund für ihre Doppelbrechung gelegen sein und die Annahme doppelbrechender, kristallinischer Mizellen, welche Näg eli als notwendig vorausgesetzt hat, überflüssig werden.

\section{SchluBbetrachtung.}

Wäre der Vergleich der „Emulsionskolloide“ mit den sichtbaren Emulsionen ohne weiteres richtig, dann mübte nach meiner Meinung eine zweiprozentige Gelatinelösung sich ebensogut in eine 20 prozentige emulsionieren lassen, wie eine zweiprozentige Agarlösung. Dieses ist jedoch durchaus nicht der Fall: Gelatinelösungen von allen Konzentrationen mischen sich sofort miteinander, obgleich auch hier von Diffusion natürlich keine Rede sein kann. Daß diese Vermischung wirklich stattfindet, kann man leicht feststellen, wenn man die 20 prozentige Gelatine darstellt aus Gelatine, welche zuvor mit einem unlöslichen Farbstoff, wie Karmin oder Indigoblau, gefärbt ist; beim Vermischen der gefärbten Lösung mit der zweiprozentigen ungefärbten wird man sofortige und vollständige Durchdringung der beiden Flüssigkeiten beobachten. Es ist deshalb nicht recht einzusehen, warum eine Gelatinelösung an und für sich dann wohl aus emulsionierten "Tröpfchen" bestehen würde.

Nimmt man mit Wilhelm Ostwald ${ }^{6}$ ) an. daB bei einer bestimmten unteren Grenze der Tröpfchengrößle die Oberflächenspannung abzunehmen beginnt, dann erscheint es nicht berechtigt, das Wort "Emulsion" noch anzuwenden auf ein Gemisch, worin die disperse Phase aus Tröpfichen besteht, deren Größe unterhalb dieser Grenze gelegen ist. Man ist dabei in ein neues Begriffsgebiet angelangt, und ein neuer Terminus wird notwendig, ebenso wie es notwendig ist, Moleküle und lonen durch besondere Namen zu bezeichnen.

In einem solchen Sinne betrachtet, ist die neue Auffassung der sogenannten, Emulsionskolloide", wie dieselbe so klar ausgesprochen und durchgeführt ist in Wo. Ostwald's "Kolloidchemie", auch für mich aunehmbar und der Ausdruck einer sehr fruchtbaren physikalischen Theorie. Sichtbare Enulsionen mögen diese Theorie anschaulich gemacht haben, ihre Eigenschaften sind ganz andere, wie diejenigen, welche die Kolloide charakterisieren. Und wenn es sich herausstellen sollte, daß die Eigenschaften der "Emulsionskolloide" nur erklärt werden können, wenn man annimmt, dak die Lösungen derselben aus kleinen wasserhaltigen Subs tanzmengen bestehen, welche im Dispersionsmittel schweben, dann müssen diese Substanzmengen derart charakterisiert sein, dak sie sich prinzipiell von den Tröpfchen der milkroskopischen Emulsionen unterscheiden.

6. GrundriB der allgemeinen Chemie, 4. Aufl., 545 (1909).

\section{Ueber die Lösungen des blauen Molybdänoxyds.}

Von A. Dum a n ski.

(Eingegangen am 7. April 1910)

Das blaue Molybdänoxyd gehört noch heute zu den wenig bekannten und untersuchien Verbindungen, obwohl es schon durch J.J. Berzelius ${ }^{1}$ ), C. F. Rammelsberg ${ }^{2}$ ) entdeckt und durch W.

5) Pogg. Ann. 6, 385 (1887).

3) Pogg. Ann. 127, 290 (1887).
Muthman $n^{3}$ als chemisches Individuum erkannt wurde. Seine Lösungen erhielt man sowohl in kolloidem als auch kristalloidem Zustande. Aber es war unbekannt, ob diese beiden Modilikationen des blauen Oxyds ganz selbständig oder in-

8) Liebig's Ann. d. Chemie 238, 124 (1887). 